\title{
MODELLING HUMAN BEHAVIOUR IN THE DIGITAL ERA: ECONOMIC AND SOCIAL IMPACTS
}

\author{
Elena de la Poza ${ }^{1}$, Lucas Jódar ${ }^{2}$
}

date of paper receipt:

17.04.2019.

Review Article date of sending to review:

19.04.2019.

doi: 10.2478/eoik-2019-0015 date of review receipt:

07.05.2019.

UDK: 004.738.5:658.8

\footnotetext{
${ }^{1}$ Universitat Politècnica de València, Camino de Vera s/n. 46022, Valencia, Spain
}

\begin{abstract}
This paper critically analyses the implications the digitalisation process has on individuals and organization 's behaviour. The digital era has positive aspects such as the access to information on real time from almost any geographical place combined with the shorten the length of time of processes. In addition, new economic trends and paradigms emerge in the digital era. However, we cannot deny the existence of negative or at least unexpected aspects of the digitalization. This work highlights some of the most alarming aspects of digitization that require the attention and implementation of measures by public authorities to prevent from the collateral damages the digitalisation can produce on citizenship well-being.
\end{abstract}

\section{Keywords:}

digitalisation; behaviour; socio-economic impact; robotisation; hyper connection era; metric criteria; performance assessment. 


\section{INTRODUCTION}

Digitalisation, understood as the mass access of most of the population to the Internet and to products and/ or services from mobile and/or set platforms, strongly impacts society because it affects the economy and social behaviour habits.

From the economy point of view, technology allows increased productivity because it extends contacts between sellers and customers in terms of the number and time of the seller-buyer interaction [1], which reduces transaction costs.

At the same time, high-risk collateral effects come into play. Like all revolutions, there is an initial stage with mass job destruction, and then the subsequent creation of new jobs. Indeed many bank branches, travel agencies, employers of distribution services and jobs in physical shops have disappeared or intend to. Shortly afterwards, administrative-type jobs disappear given the continuous digitisation and robotisation process that is reaching sectors like agriculture.

In the initial stage, when mass job loss occurs, tax issues are complicated and new formulae to capture income via State taxes must be sought because the traditional formula is relegated. If the technology revolution is accompanied by the State being slow in making reforms, particularly reforms in the occupational domain, then technological beneficiaries are the stakeholders (businesspeople or employees) in the market that first adapt to the technology. Indeed technology-based companies appear that facilitate products and services, and the most demanded job posts are those requiring ITC skills. One of the consequences is a lower price due to the reduction in marginal costs, which also benefits rational customers.

\section{SOCIO-ECONOMIC IMPACTS OF THE TECHNOLOGICAL REVOLUTION}

As Damasio [2] stated (2018), people are moved by emotions and technology, the so-called Big Data, which is mainly Internet user's intimacy being violated by platforms allowed to sell much more online, which increases logistic work, packaging, courier services, transport, etc.

The most important effects are jobs being destroyed, precarious work, tax evasion, and with all this, inequality grows. One of the key factors in this process is that salaries do not increase as a result of the loss of workers' negotiation. This situation must ultimately be due to lack of government measures to watch over workers. In short, we cannot blame robots, but political leaders [3].

In other words, robotisation destroys jobs and creates other (more qualified) ones, but salaries worsen because politicians do not act by not making policies to motivate training and recycling workers; that is, they do not anticipate changes, and even if they do, they do not occur as quickly as the pace at which the market moves. Consequently, employers make the most of this gap and (some) pay as little as possible [4]. However, the worst consequence we are witnessing as a result of technology abuse is the appearance of social diseases. The effect of technology is positive when it is used consciously as a tool for improving processes, reaching labour goals and enhancing progress. However, when technology is used limitless and unconsciousness it can destroy individuals moral and lives.

Being addicted to games, betting, pornography and shopping are very serious diseases that are copied in other people, and how it can be stopped is unknown.

Nowadays, young children are addicted to screens, videogames and being permanently busy using digital means that make correct education, motivation to make efforts, paying attention and empathy difficult, and personal relationships are relegated to a digital relationship based on an image and a constant image of happiness.

Screen (technology-related) abuse makes individuals impatient and superficial, and they are unable to endure anything. It isolates people and encourages individuals' solitude. Proof of this is British government creating a Ministry of Solitude which paradoxically emerges during the hyper connection era that the Internet and social networks provide. 


\section{RISKS IN THE DIGITAL ERA}

Nowadays, technological progress has placed at our disposal vast amounts of information, but we cannot or do not know how to discriminate it. Although it is true that technology helps save lots of time, we also lose much more time being distracted by the digital world. We do not go into contents in-depth, being superficial is encouraged, and not only when studying or solving problems, but also in occupational and personal relationships with individuals. Moreover, the number of contacts and communication frequency increase, but the quality of relations does not.

Risks go beyond information on platforms, which compile information about people decisions' by "spying on individuals" and using artificial intelligence, which can even change the electoral performance of a population that normally uses digital media by sending it information (not necessarily "fake news"), which is segmented and adapted to its profiles. In fact online misinformation on a grand scale and the potential for digital wildfires were listed by the World Economic Forum [5] in 2016 as some of the major risks of our society.

In short, population has lost freedom and intimacy because is monitored and can end up doing what others (with access to information) want; that is, interests that go beyond individuals model their behaviour, and their activity is at third parties' service.

Apparently with data being more accessible, information automatically improves the assessments made of activities (regardless of them being business, physical; i.e., or those performed by an individual or by organisations). This fact is much more relevant than it would appear because many people's professional promotion is at risk and, as cited later on, so is people's health or security.

Assessments are certainly necessary because what is not assessed can be devalued by laziness, convenience or lack of motivation. However as pointed out earlier, humans are taken in by their emotions [2], and thus assessment criteria have to be designed in such a way that they attempt to reduce, or eliminate, perverse effects like greed, vanity or impatience.

However, more data do not necessarily mean better information. Information has to be analysed to remove repetitions that are not apparent, or voluntarily concealed. "Lots of little bits make a lot", but many poor averages do not spell excellence, but plenty of mediocrity.

The cobra effect deserves special attention when evaluating human performance. It occurs when an attempted solution to a problem makes the problem worse, and acts like a kind of unintended consequence. The term is used to illustrate the causes of incorrect stimulation in economy and politics [6].

In other words, an appropriate evaluation criterion may produce a bad evaluation.

\section{USE OF METRICS IN PERFORMANCE ASSESSMENTS}

Evaluating complex human activity cannot be done metrically, and the quantity of outputs does not determine what is better when comparing different questions. What is more, they can encourage mistaken or fraudulent activity to obtain a better score. What is most impressive might not be the best, but may even be a great mediocrity instead of excellence [7].

Metric criteria based on quantity mean an objective seducer aspect for scientists, which may objectively appear false [8].

How can the activity of a teacher, researcher, doctor, police officer, company, etc., be assessed?

It is not true to state that the best teacher is (s)he who passes more students, nor is the best research (s) he who publishes more articles. The best doctor is not necessarily the most successful one, and the best businessperson does not necessarily sell the most products if they are not well measured.

However, what is even worse than bad criteria, given their imperfection, is the perverse trend/s that these criteria produce, like approving someone who does not deserve it: like introducing fraud into research, not attending a difficult patient, or confirming that someone innocent has committed a crime [9].

Some theories demonstrate just how complicated assessing human activity is $[6,10]$, and how using numerical metrics for these assessments is not suitable [11].

Assessment criteria must take into account:

Include quantitative and qualitative criteria

Limit each one and analyse the level of repetition

Demand sufficient experience 
Demand variety in production and innovation

The metric criteria that appeared in the 1960s in the USA and applied by Robert MacNamara were shown to be unsuitable for assessing the management of military conflicts, especially the Vietnam War [12]. What is surprising is that they are still widely used by public management agents in Europe.

Metric criteria failed during the Vietnam War because the war was not won by the side with the fewest deaths, but by the side that managed to exhaust its rival. The side with the most victims can resist, and can win [13].

In an assessment of researchers, the determining criterion cannot be the number of publications, not even the journals selected. This criterion implies maximising the quantity of publications and ignores innovation by repeating and concealing ideas, avoiding risky research and, what is worse, improperly educating young researchers in such practices.

The seriousness of criteria firstly lies in being considered good and are, thus, never corrected. Moreover, even though researchers realise, they have to follow the rules of the game because they will be evaluated with these criteria in order to be promoted. So they are imprisoned by a perverse criterion [14].

In the digital domain, new indicators constantly appear that measure the performance of organisations from economic, social or more complex areas. Some examples are environmental indicators, which encompass the three aforementioned areas. These indicators, some of which offer public access, and others private access, quantify the performance of organisations over time, and their position in relation to competitor organisations and to industry as a whole. It is interesting to observe how harmony does not often exist in the results obtained by the various indicators created for one same company. This is explained by the different algorithms used to quantify the performance of organisations [15].

Recently, many indicators have emerged that quantify customer perceptions of the products and/or services received physically or digitally. In any case, these indicators become a powerful digital marketing tool assessed by service companies.

Thus the position occupied by restaurants or hotels depends not so much on their performance, but on how users perceive them, who decide to publicly provide opinions about their perception of the received service.

\section{CONCLUSIONS}

This paper highlights the relevance and effect of digitalisation on individual's behaviour. Undoubtedly digitalisation transforms our habits and the way we perform on daily basis but also organizational processes and management. A positive impact of the digitalisation is the blooming of new sectors of economic activity, such as technology-based companies, which facilitate products and services and demand highly skilled jobs. Ina addition, digitalisation benefits rational customers due to the reduction in production costs. On the other hand, the technological revolution causes negative impacts such as the rise of precarity and social inequality and its abuse has brought the appearance of social diseases.

The possible compilation of information and the techniques for its management has created a myriad range of metrics that attempt to measure what we do, produce, expect and desire as consumers, but also as workers, patients, provider, etc. The intrinsic risks of a meta-metric system arise when the quantity superimposes on quality. Digitalisation has not only brought this meta-metric system but also has generated the belief of being top rank adds value to individuals and organizations when it is not often the case. Pervasive individual strategies can flood in organizations trying to manage individual's behaviour looking for the high-performance of organizations. In addition, digitalisation fosters individual's hyper connection, which derive in constant but superficial relationship that instead of enriching individuals' spirits impoverish them. 


\section{REFERENCES}

[1] J. Rifkin. (2011) The Zero Marginal Cost Society. New York: Palgrave Macmillan.

[2] A. Damasio. (2018). The Strange Order of Things. Life, Feelings, and the Making of Cultures. Barcelona, Spain: Planeta (in Spanish).

[3] P. Krugman. Los robots no tienen la culpa de los precios bajos, El Pais, 17 Marzo, 2019. (in Spanish). Available at: https://elpais.com/economia/2019/03/15/actualidad/1552651704_169047.html

[4] R. Botsman. Who Can You Trust? How Technology Brought Us Together and Why It Could Drive Us Apart, Penguin Random House, 2017.

[5] World Economic Forum, Digital Wildfires in a Hyperconnected World, 2016.

[6] C.A.E. Goodhart. Money, Information and Uncertainty, The McMillan Press Ltd., London, 1975.

[7] S.E. Merry. The Seduction of Quantification: Measuring Human Rights, Gender Violence, and Sex Traffiquing, The University of Chicago Press, Chicago, 2016

[8] T.M. Porter. Trust in Numbers: The Pursuit of Objetivity in Science and Public Life, Princeton Univ. Press, Princeton, 1995.

[9] K. Cukier and V. Mayer-Schonberger. The Dictatorship of Data, MIT Technology Review, may, 2013. [10] D.T. Campbell. Assessing the Impact of Planned Social Change, The Public Affairs Center, Darmouth College, New Hampshire, USA, 1976.

[11] J.Z. Muller. The Tyranny of Metrics, Princeton Univ. Press, Princeton, 2018

[12] J.S. Baskin. According To U.S. Big Data, We Won The Vietnam War, Forbes Magazine, 2014. Available at:https://www.forbes.com/sites/jonathansalembaskin/2014/07/25/according-to-big-data-we-won-thevietnam-war/\#395975054c5a

[13] E.N. Luttwak. The Pentagon and the Art of War, Simon and Schuster, New York 1985.

[14] D. Ravitch. The Death and Life of Great American School System, Basic Books, New York, 2010.

[15] M.A. Alcaide, E. De La Poza \& N. Guadalajara. Assessing the Sustainability of High-Value Brands in the IT Sector. Sustainability 2019, 11, 1598. 